\title{
Long-term real-world entecavir therapy in treatment-naïve hepatitis B patients: base-line hepatitis B virus DNA and hepatitis B surface antigen levels predict virologic response
}

Ju-Yeon Cho ${ }^{1,2}$, Won Sohn ${ }^{1,3}$, Dong-Hyun Sinn ${ }^{1}$, Geum-Youn Gwak ${ }^{1}$, Yong-Han Paik ${ }^{1}$, Moon Seok Choi ${ }^{1}$, Kwang Cheol Koh ${ }^{1}$, Seung Woon Paik ${ }^{1}$, Byung Chul Yoo ${ }^{1}$, and Joon Hyeok Lee ${ }^{1}$

\begin{abstract}
${ }^{1}$ Department of Medicine, Samsung Medical Center, Sungkyunkwan University School of Medicine, Seoul; ${ }^{2}$ Department of Medicine, Chosun University Hospital, Gwangju; ${ }^{3}$ Department of Hepatology, Daejin Medical Center, Bundang Jesaeng Hospital, Seongnam, Korea
\end{abstract}

Received: March 24, 2016

Revised : May 22, 2016

Accepted: June 4, 2016

\author{
Correspondence to \\ Joon Hyeok Lee, M.D. \\ Department of Medicine, \\ Samsung Medical Center, \\ Sungkyunkwan University \\ School of Medicine, 81 Irwon-ro, \\ Gangnam-gu, Seoul o6351, Korea \\ Tel: +82-2-3410-3409 \\ Fax: +82-2-3410-6983 \\ E-mail: liverjhlee@skku.edu
}

Background/Aims: Entecavir is a potent nucleoside analogue with high efficacy and barrier for resistance. We aimed to investigate the long-term efficacy and viral resistance rate of entecavir and explore the factors associated with virologic response, including quantitative hepatitis B surface antigen (qHBsAg) levels.

Methods: One thousand and nine treatment-naïve chronic hepatitis B (CHB) patients were evaluated for cumulative rates of virologic response, biochemical response, and entecavir mutations. The role of baseline qHBsAg for virologic response was assessed in 271 patients with qHBsAg prior to entecavir treatment.

Results: The median duration of entecavir treatment was 26.5 months. The cumulative rate of virologic response at years 1, 3, and 5 were $79.0 \%, 95.6 \%$, and $99.4 \%$, respectively. The cumulative rate of entecavir resistance was $1.0 \%$ and 2.1\% in years 3 and 5. Multivariate analysis identified baseline hepatitis B e antigen $(\mathrm{HBeAg})$ negative status $(p<0.001)$ and lower hepatitis B virus $(\mathrm{HBV})$ DNA $(p$ $<0.001$ ) as predictors of virologic response. Lower qHBsAg was an independent predictor of virologic response in patients with baseline qHBsAg. There were no serious adverse events during treatment.

Conclusions: Long-term entecavir treatment of nucleos(t)ide-naïve CHB patients was associated with an excellent virologic response and a low rate of entecavir-resistant mutations at 5 years. Baseline HBV DNA load, qHBsAg levels, and HBeAg status were predictors of virologic response during entecavir treatment.

Keywords: Hepatitis B virus; Entecavir; Quantitative hepatitis B surface antigens; Virologic response

\section{INTRODUCTION}

Hepatitis B virus (HBV) is estimated to have infected more than 2 billion people worldwide, of whom 350 to 400 million people are chronically infected [1]. Chronic hepatitis $\mathrm{B}(\mathrm{CHB})$ patients are at an increased risk for liver-related complications, including cirrhosis, liver failure, hepatocellular carcinoma, and death [2]. The Risk Evaluation of Viral Load Elevation and Associated Liver Disease/Cancer (REVEAL) study demonstrated that progression to liver cirrhosis and hepatocellular carcinoma are strongly correlated with HBV DNA loads 
$[3,4]$. Therefore, the goals of treatment for CHB patients are to suppress HBV viral replication to undetectable levels and achieve prevention of cirrhosis and hepatocellular carcinoma $[5,6]$.

Entecavir is a high efficacy guanosine nucleoside analogue (NUC) with a selective polymerase inhibitor of HBV replication. Among hepatitis B e antigen (HBeAg)-positive and HBeAg-negative patients at 48 weeks into their treatment, the rates of virologic response, biochemical response, and improvement of histological findings were significantly greater among patients receiving entecavir than those receiving lamivudine [7,8]. Extension of these studies demonstrated that, with prolonged treatment, higher rates of virologic response are achieved [9]. Moreover, the development of drug resistance is reported to occur at a rate of only $1.2 \%$ after 5 years of entecavir treatment in treatment-naïve CHB patients [10].

Compared to registration studies, real-world populations are more heterogeneous in terms of age and types of comorbidities; therefore, real-world data are required to confirm drug efficacies and monitor drug safety. Empirical data about entecavir use have been found to be similar to data from registration trials, with high efficacy and a good safety profile. However, these empirical studies are limited by their small enrollment numbers, short follow-up periods, and focus on Western populations [11].

In patients treated with antiviral agents, outcomes that include worse clinical prognosis in CHB patients with inadequate virologic response emphasize the need for biomarkers that can predict treatment outcomes $[12,13]$. These markers could identify patients with poor clinical outcomes and aid in individualizing therapy for them. Baseline and on-treatment response of HBV DNA loads are well known predictors of treatment outcomes for patients on antiviral therapy. Recently, quantitative hepatitis B surface antigen (qHBsAg) has been developed as a marker for evaluating viral replication and a predictor of treatment response in patients treated with interferon. However, currently there is limited data on the role of qHBsAg levels in CHB patients treated with oral antiviral therapy.

The aims of this study were to investigate the longterm efficacy and viral resistance of entecavir therapy in a real world setting and to explore the factors associated with virologic response, including qHBsAg levels.

\section{METHODS}

\section{Patients and treatment}

One thousand and nine consecutive treatment-naïve HBV-infected patients, whose treatment was initiated with $0.5 \mathrm{mg}$ of daily entecavir at Samsung Medical Center from 2007 through 2012, were enrolled. All patients were chronically infected with HBV and were confirmed as HBsAg-positive for at least 6 months. Exclusion criteria consisted of coinfection with hepatitis $\mathrm{C}$ virus or human immunodeficiency virus, prior treatment history with NUCs or interferon, entecavir treatment less than 24 weeks, prior diagnosis of hepatocellular carcinoma, being younger than 18 years old, and insufficient clinical data (Fig. 1). The indication for antiviral therapy followed those of the Korean Association for the Study of the Liver guidelines [14] and included: HBeAg-positive CHB patients with HBV DNA loads of $\geq 20,000 \mathrm{IU} / \mathrm{mL}$ and alanine transaminase (ALT) levels of $\geq 2 \times$ the upper normal limit (UNL), HBeAg-negative CHB patients with HBV DNA loads $\geq 2,000 \mathrm{IU} / \mathrm{mL}$ and an ALT level of $\geq 2 \times$ the UNL, compensated cirrhotics with HBV DNA loads $\geq 2,000 \mathrm{IU} / \mathrm{mL}$ regardless of the ALT level, and decompensated cirrhotics with any detectable HBV DNA loads.

This study was approved by the Institutional Review Board of Samsung Medical Center (IRB 2014-03-158).

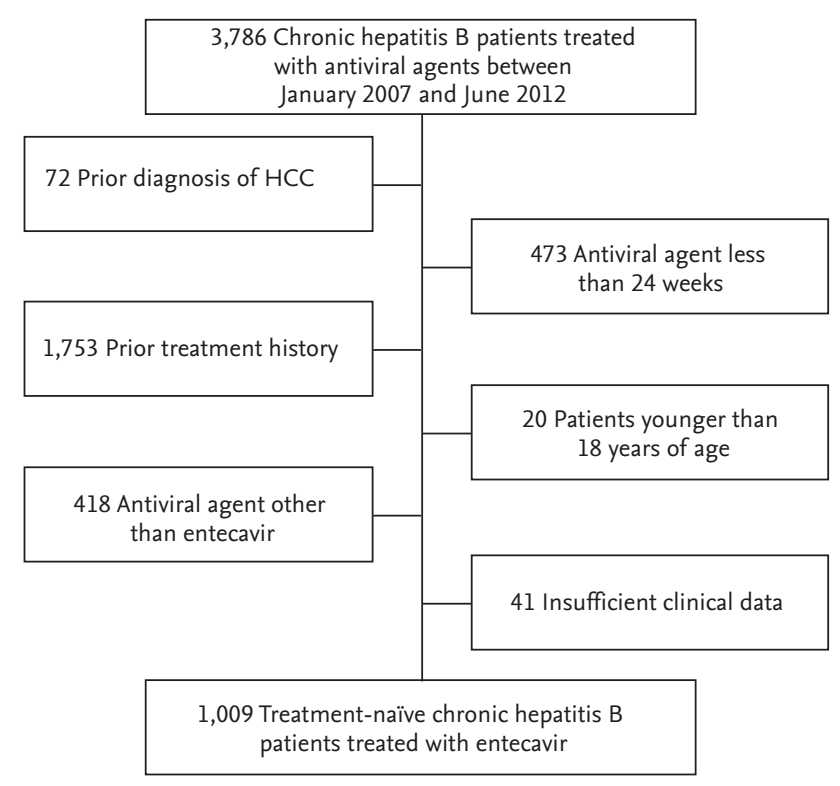

Figure 1. Flow chart of patients included in the study. 


\section{Assessment}

All patients underwent complete blood counts, liver function tests, HBV virologic markers, HBV DNA load counts, and imaging studies (abdominal sonography, computed tomography, or magnetic resonance imaging); these assessments were completed at baseline and were repeated at 3- to 6-month intervals. HBsAg, anti-HBs antibody, HBeAg, and anti-HBe antibody levels were examined by enzyme immunoassay. HBsAg levels were quantified by automated chemiluminescent microparticle immunoassay (Architect HBsAg, Abbott, IL, USA). HBV DNA loads were measured using the COBAS TaqMan HBV quantitative test (Roche Molecular Systems Inc., Branchburg, NJ, USA), with a lower detection limit of $<9 \mathrm{IU} / \mathrm{mL}$. Viral mutational analysis was performed by direct sequencing of the reverse transcriptase (RT) domain of the HBV polymerase gene. Virologic responses were defined as a reduction in HBV DNA loads to $<60 \mathrm{IU} / \mathrm{mL}$. Biochemical response was defined as ALT $<40 \mathrm{U} / \mathrm{L}$. Virologic breakthroughs were defined as an increase in serum HBV DNA loads by $>1 \log _{10}$ above the nadir after achieving a virologic response during continued treatment. Liver cirrhosis was determined by liver biopsy or an imaging modality combined with two positive laboratory findings (e.g., platelet levels < $100,000 / \mu \mathrm{L}$, albumin levels $<3.5 \mathrm{~g} / \mathrm{dL}$, or prothrombin time $[\mathrm{PT}$, international normalized ratio] $>1.3$ ).

\section{Statistical analyses}

Baseline characteristics were summarized with descriptive statistics and are presented as a mean \pm standard deviation or as percentages. In all study subjects, continuous variables were compared parametrically using the Student $t$ test or non-parametrically using the Mann-Whitney $U$ test. Categorical variables were compared using the chi-square test or the Fisher exact test as appropriate. Cumulative rates of virologic and biochemical responses were analyzed using the Kaplan-Meier method. Independent risk factors predicting achievement of virologic response and viral resistance were analyzed with the stepwise Cox regression analysis. A two-sided $p<0.05$ was considered statistically significant. All statistical analyses were performed using SPSS version 19.0 (IBM Co., Armonk, NY, USA).

\section{RESULTS}

\section{Patient demographics}

Baseline patient characteristics are listed in Table 1. The majority of patients were male (64.5\%) and the median patient age was 48 years old (range, 18 to 80 ). The patients were followed up for a median of 28.0 months (range, 6.o to 77.4). Five hundred and seventy-one (56.6\%) patients were HBeAg-positive and 438 patients (43.4\%) were HBeAg-negative. The mean baseline HBV DNA load was $6.47 \pm 1.40 \log _{10} \mathrm{IU} / \mathrm{mL}$ and $36.2 \%$ of the patients had liver cirrhosis at initiation of entecavir treatment. Stored baseline serum samples were available for qHBsAg analysis in 271 patients and retrospective mea-

Table 1. Baseline characteristics of treatment-naïve patients (n= 1,009)

\begin{tabular}{lc}
\hline Variable & Value \\
\hline Male sex & $651(64.5)$ \\
\hline Age, yr & $48(18-80)$ \\
\hline Duration of follow-up, mon & $28.0(6.0-77 \cdot 4)$ \\
\hline Duration of ETV & $26.5(6.0-77 \cdot 4)$ \\
administration, mon & $571(56.6): 438(43.4)$ \\
HBeAg $(+): H B e A g(-)$ patients & $6.47 \pm 1.40$ \\
\hline HBV DNA, log 10 IU/mL & $365(36.2)$ \\
\hline Liver cirrhosis & $3.59 \pm 0.69$ \\
qHBsAg, $\log _{10}$ IU/mL ${ }^{\mathrm{a}}$ & $5.08 \pm 1.61$ \\
WBC, $\times 10^{3} / \mu \mathrm{L}$ & $14.3 \pm 1.8$ \\
\hline Hemoglobin, g/dL & $152.2 \pm 62.4$ \\
\hline Platelet, $\times 10^{3} / \mu \mathrm{L}$ & $112.8 \pm 183.9$ \\
\hline AST, U/L & $154.7 \pm 292.3$ \\
\hline ALT, U/L & $1.27 \pm 1.93$ \\
\hline Total bilirubin, mg/dL & $3.9 \pm 0.5$ \\
\hline Albumin, g/dL & $1.13 \pm 0.19$ \\
\hline Prothrombin time, INR & \\
\hline
\end{tabular}

Values are presented as number (\%), median (range), or mean $\pm \mathrm{SD}$.

ETV, entecavir; HBeAg, hepatitis B e antigen; HBV, hepatitis $B$ virus; qHBsAg, quantitative hepatitis B surface antigen; WBC, white blood cell; AST, aspartate aminotransferase; ALT, alanine transaminase; INR, international normalized ratio.

${ }^{\mathrm{a}}$ Results from 271 patients. 

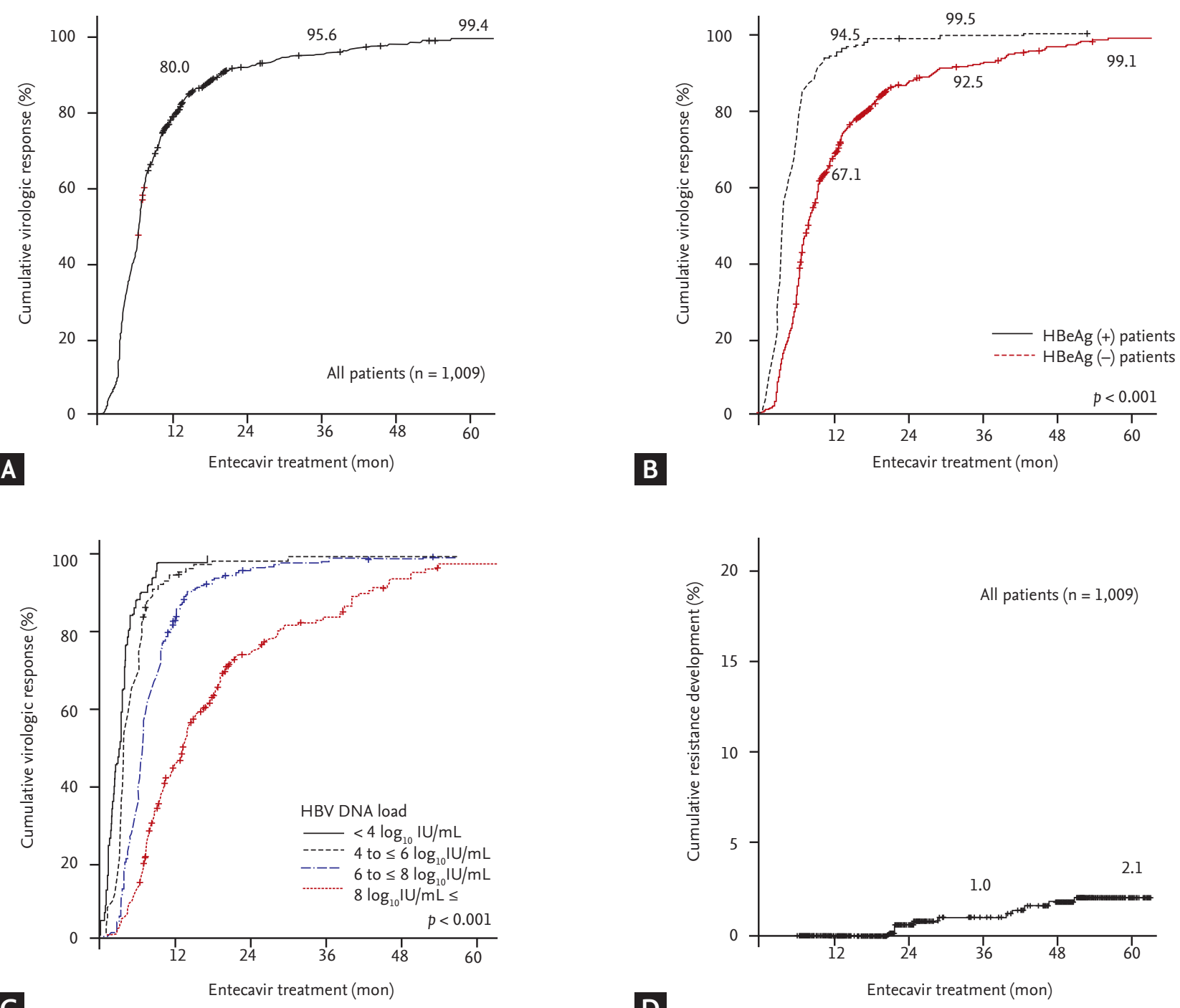

Figure 2. Virologic response of patients on continuous entecavir treatment. (A) The cumulative virologic response rate increased with time, reaching 99.4\% at year 5. (B) Hepatitis B e antigen (HBeAg)-negative patients had a statistically higher rate of virologic response at year 1, 3, and 5. (C) The cumulative virologic response rate in patients with high hepatitis B virus (HBV) DNA loads, compared to patients with HBV DNA loads $<4 \log _{10} \mathrm{IU} / \mathrm{mL}$ resulted in a significantly lower virologic response. (D) The log-rank test was used to compare the differences in the viral responses between each group. The cumulative entecavir resistance rates were $0 \%$ after 1 year, $1.0 \%$ after 3 years, and $2.1 \%$ after 5 years.

surement of qHBsAg in these patients revealed a median of $3,668.5 \mathrm{IU} / \mathrm{mL}$ (range, 1.15 to $124,925.0$ ).

\section{Entecavir efficacy}

Among 1,009 patients, the cumulative biochemical response rates were $81.0 \%, 95.0 \%$, and $99.5 \%$ at years 1,3 , and 5 , respectively. The cumulative virologic response rates in the entecavir-treated patients were $80.0 \%, 95.6 \%$, and $99.4 \%$ at years 1, 3, and 5, respectively (Fig. 2A). Six- ty-four patients (6.3\%) failed to achieve a virologic response during follow-up. The cumulative virologic response rate in HBeAg-negative patients, which was $94.5 \%$ after the first year and $99.5 \%$ after the third year, was significantly higher than that of HBeAg-positive patients, which was 67.1\% after the first year and $92.5 \%$ after the third year ( $p$ $<0.001$ ) (Fig. 2B). Compared to patients with HBV DNA loads $<4 \log _{10} \mathrm{IU} / \mathrm{mL}$, patients with higher HBV DNA loads had a significantly lower virologic response $(p \leq$ 
Table 2. Univariate and multivariate analysis of factors associated with virologic response in entecavir-treated chronic hepatitis B patients $(n=1,009)$

\begin{tabular}{|c|c|c|c|c|}
\hline \multirow{2}{*}{ Variable } & \multicolumn{2}{|c|}{ Univariate } & \multicolumn{2}{|c|}{ Multivariate } \\
\hline & $\operatorname{HR}(95 \% \mathrm{CI})$ & $p$ value & $\operatorname{HR}(95 \% \mathrm{CI})$ & $p$ value \\
\hline Age, yr & $1.015(1.009-1.022)$ & $<0.001$ & & \\
\hline Male sex & $1.008(0.883-1.152)$ & 0.904 & & \\
\hline Liver cirrhosis & $1.472(1.288-1.682)$ & $<0.001$ & & \\
\hline HBV DNA, $\log _{10} \mathrm{IU} / \mathrm{mL}$ & $0.615(0.587-0.644)$ & $<0.001$ & 0.671 (0.635-0.709) & $<0.001$ \\
\hline $\operatorname{HBeAg}(-)$ & $0.347(0.303-0.397)$ & $<0.001$ & $0.607(0.521-0.708)$ & $<0.001$ \\
\hline $\mathrm{WBC}, \times 10^{3} / \mu \mathrm{L}$ & $0.949(0.910-0.988)$ & 0.012 & & \\
\hline Hemoglobin, g/dL & $0.967(0.934-1.002)$ & 0.061 & & \\
\hline Platelet, $\times 10^{3} / \mu \mathrm{L}$ & $0.997(0.996-0.998)$ & $<0.001$ & & \\
\hline AST, U/L & $1.000(1.000-1.000)$ & 0.588 & & \\
\hline ALT, U/L & $1.000(1.000-1.000)$ & 0.438 & & \\
\hline Total bilirubin, mg/dL & $1.032(1.001-1.064)$ & 0.045 & & \\
\hline Albumin, g/dL & $1.096(0.957-1.255)$ & 0.187 & & \\
\hline Prothrombin time, INR & $2.177(1.621-2.922)$ & $<0.001$ & & \\
\hline
\end{tabular}

HR, hazard ratio; CI, confidence interval; HBV, hepatitis B virus; HBeAg, hepatitis B e antigen; WBC, white blood cell; AST, aspartate aminotransferase; ALT, alanine transaminase; INR, international normalized ratio.

0.001 ) (Fig. 2C).

Univariate analysis revealed that older age, presence of liver cirrhosis, lower HBV DNA load, HBeAg negativity, lower platelet count, and prolonged PT were statistically significant factors associated with virologic response. In multivariate analysis, only HBeAg-negativity and lower HBV DNA load were independently associated with virologic response (Table 2).

The cumulative HBsAg seroclearance rates were $0.4 \%$, $0.7 \%$, and $1.6 \%$ in years 1,3 , and 5 , respectively. Among the $571 \mathrm{HBeAg}$-positive patients, the cumulative $\mathrm{HBeAg}$ seroclearance rates at years 1, 3, and 5 were $4.1 \%, 19.2 \%$, and $40.2 \%$, respectively.

\section{Virologic breakthroughs}

Fifty-six patients (5.9\%) experienced virologic breakthroughs during the follow-up period. Noncompliance was confirmed in 42 patients (75.0\%) and of the remaining 14 patients, virologic resistance was confirmed in 12.

\section{Virologic resistance}

Only 12 patients (1.2\%) out of the 1,009 treatment-naïve patients developed confirmable entecavir resistance. The cumulative entecavir resistance rates were o\% after 1 year, $1.0 \%$ after 3 years, and $2.1 \%$ after 5 years, respectively (Fig. 2D). The characteristics of patients who developed entecavir resistance are summarized in Table 3. The median time to resistance was 34 months (range, 21 to 66). All patients were HBeAg-positive, with a median HBV DNA load of $7.95 \log _{10}$ IU/mL (range, 5.30 to 8.04). Baseline serum samples were available in six patients with documented entecavir resistance during follow-up and an rtV214A mutation was identified in two patients.

\section{The role of $\mathrm{qHBsAg}$ levels in predicting virologic response}

Stored baseline serum samples were available in 271 patients (126 HBeAg-negative and $145 \mathrm{HBeAg}$-positive patients) and qHBsAg levels prior to entecavir treatment were measured. Multivariate analysis of the predictive factors of virologic response was performed in this 271-patient set, which revealed that lower qHBsAg levels $(p<0.001)$, lower HBV DNA loads $(p<0.001)$, and HBeAg-negative status $(p=0.005)$ were independently 
Table 3. Characteristics and mutation sites of entecavir-resistance confirmed patients

\begin{tabular}{|c|c|c|c|c|c|c|c|}
\hline Patient & Age, yr & Sex & $\mathrm{HBeAg}$ & $\begin{array}{l}\text { HBV DNA, } \\
\log _{10} \mathrm{IU} / \mathrm{mL}\end{array}$ & $\begin{array}{c}\text { Time to } \\
\text { resistance, mon }\end{array}$ & $\begin{array}{l}\text { Baseline } \\
\text { mutation }\end{array}$ & Confirmed mutation \\
\hline 1 & 48 & $\mathrm{~F}$ & + & 7.87 & 51 & None & $\mathrm{rtM} 2 \mathrm{O}_{4} \mathrm{~V}+\mathrm{rtL} 18 \mathrm{oM}, \mathrm{rtS} 2 \mathrm{O}_{2} \mathrm{G}$ \\
\hline 2 & 54 & $\mathrm{~F}$ & + & 8.04 & 47 & - & rtM204V+rtL18oM, rtS2O2G \\
\hline 3 & 60 & $\mathrm{~F}$ & + & 7.05 & 22 & - & $\mathrm{rtM} 2 \mathrm{O}_{4} \mathrm{~V}+\mathrm{rtL} 18 \mathrm{OM}, \mathrm{rtS} 2 \mathrm{O}_{2} \mathrm{G}$ \\
\hline 4 & 43 & M & + & $7 \cdot 72$ & 41 & None & rtM204V+rtL18oM, rtM250L \\
\hline 5 & 55 & $\mathrm{~F}$ & + & 7.17 & 21 & $\mathrm{rtV} 214 \mathrm{~A}$ & rtM204V+rtL18oM, rtT184L \\
\hline 6 & 67 & M & + & 8.04 & 25 & - & rtM204V+rtL18oM, rtT184S \\
\hline 7 & 58 & M & + & 7.17 & 22 & - & rtM204V+rtL18oM, rtN238H, rtT184A \\
\hline 8 & 38 & M & + & 8.04 & 43 & None & rtM204V+rtL18oG, rtN238H \\
\hline 9 & 40 & M & + & 8.04 & 29 & None & $\mathrm{rtM2O} 4 \mathrm{I}$ \\
\hline 10 & 49 & $\mathrm{~F}$ & + & 8.04 & 22 & - & $\mathrm{rtM} 2 \mathrm{O}_{4} \mathrm{I}$ \\
\hline 11 & 38 & M & + & $5 \cdot 30$ & 66 & $\mathrm{rtV} 214 \mathrm{~A}$ & rtM204I, rtV173L, rtM250V \\
\hline 12 & 32 & M & + & 8.04 & 40 & - & rtI169L \\
\hline
\end{tabular}

HBeAg, hepatitis B e antigen; HBV, hepatitis B virus.

Table 4. Univariate and multivariate analysis of factors associated with virologic response in entecavir-treated chronic hepatitis B patients with baseline $\mathrm{qHBsAg}(\mathrm{n}=\mathbf{2 7 1})$

\begin{tabular}{|c|c|c|c|c|}
\hline \multirow{2}{*}{ Variable } & \multicolumn{2}{|c|}{ Univariate } & \multicolumn{2}{|c|}{ Multivariate } \\
\hline & $\operatorname{HR}(95 \% \mathrm{CI})$ & $p$ value & $\operatorname{HR}(95 \% \mathrm{CI})$ & $p$ value \\
\hline Age, yr & $1.019(1.006-1.032)$ & 0.005 & & \\
\hline Male sex & $0.883(0.685-1.139)$ & 0.339 & & \\
\hline Liver cirrhosis & $1.539(1.190-1.990)$ & 0.001 & & \\
\hline $\mathrm{HBV}$ DNA, $\log _{10} \mathrm{IU} / \mathrm{mL}$ & $0.598(1.190-1.990)$ & $<0.001$ & $0.674(0.607-0.749)$ & $<0.001$ \\
\hline $\mathrm{qHBsAg}, \log _{10} \mathrm{IU} / \mathrm{mL}$ & $0.499(0.426-0.585)$ & $<0.001$ & $0.681(0.563-0.825)$ & $<0.001$ \\
\hline $\operatorname{HBeAg}(-)$ & $0.354(0.274-0.457)$ & $<0.001$ & $0.673(0.512-0.887)$ & 0.005 \\
\hline $\mathrm{WBC}, \times 10^{3} / \mu \mathrm{L}$ & $0.957(0.887-1.031)$ & 0.248 & & \\
\hline Hemoglobin, g/dL & $0.992(0.924-1.065)$ & 0.827 & & \\
\hline Platelet, $\times 10^{3} / \mu \mathrm{L}$ & $0.996(0.995-0.998)$ & $<0.001$ & & \\
\hline AST, U/L & $0.999(0.998-1.000)$ & 0.119 & & \\
\hline $\mathrm{ALT}, \mathrm{U} / \mathrm{L}$ & $0.999(0.999-1.000)$ & 0.176 & & \\
\hline Total bilirubin, mg/dL & $1.070(0.892-1.284)$ & 0.464 & & \\
\hline Albumin, g/dL & $1.353(0.969-1.891)$ & 0.076 & & \\
\hline Prothrombin time, INR & $3.415(1.375-8.480)$ & 0.008 & & \\
\hline
\end{tabular}

qHBsAg, quantitative hepatitis B surface antigen; HR, hazard ratio; CI, confidence interval; HBV, hepatitis B virus; HBeAg, hepatitis B e antigen; WBC, white blood cell; AST, aspartate aminotransferase; ALT, alanine transaminase; INR, international normalized ratio. 

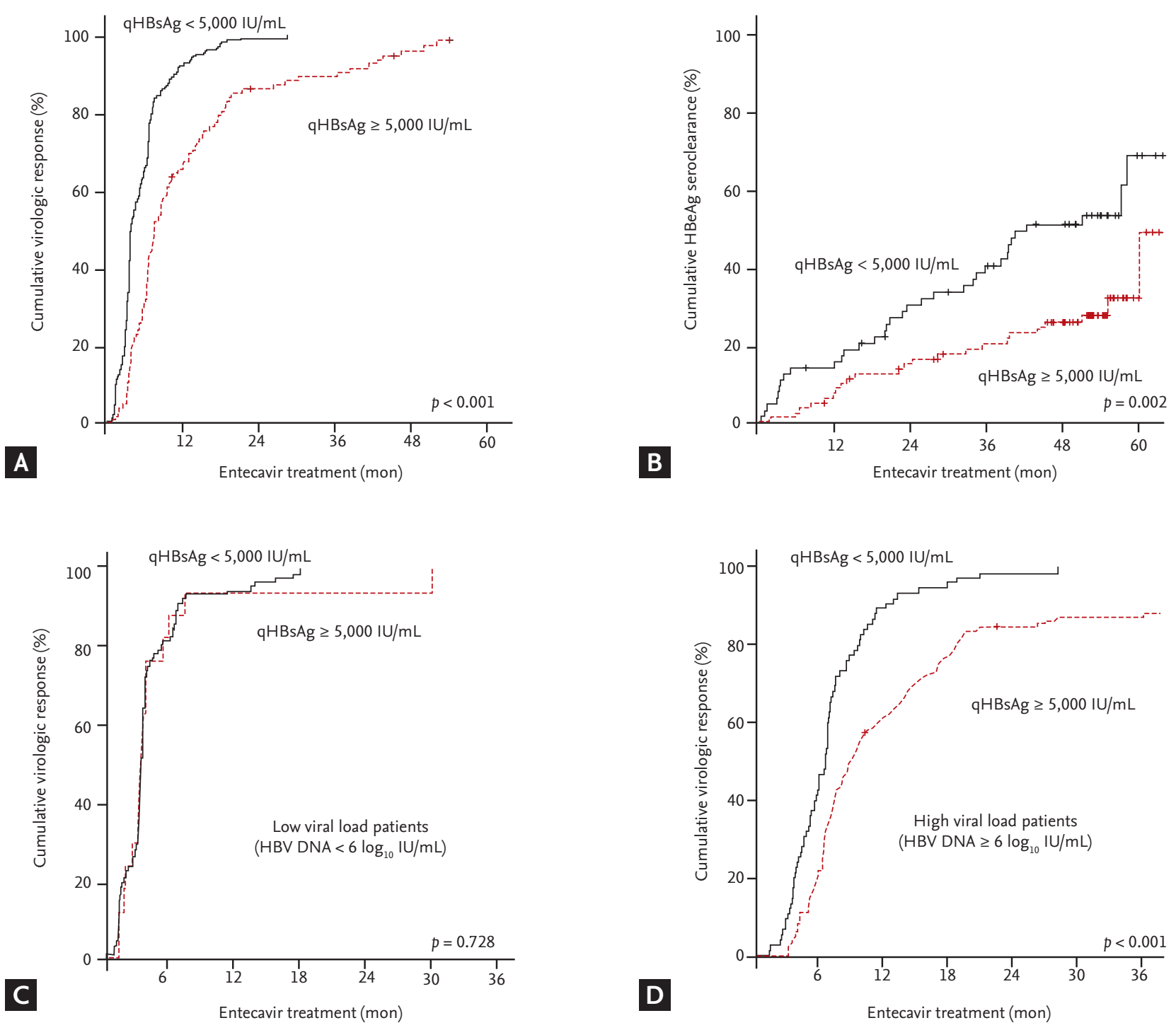

Figure 3. Virologic response and hepatitis B e antigen ( $\mathrm{HBeAg}$ ) seroclearance based on quantitative hepatitis B surface antigen (qHBsAg) level. (A) The cumulative virologic response rate was significantly greater in patients with baseline $\mathrm{qHBsAg}<5,000$ $\mathrm{IU} / \mathrm{mL}$. (B) In HBeAg-positive patients, baseline $\mathrm{qHBsAg}<5,000 \mathrm{IU} / \mathrm{mL}$ was associated with a significantly greater cumulative rate of HBeAg seroclearance. (C) The cumulative virologic response rate was not statistically different among patients with low viral loads $\left(\leq 6 \log _{10} \mathrm{IU} / \mathrm{mL}\right.$ ), regardless of qHBsAg levels. (D) In the high viral load group (high hepatitis B virus [HBV] DNA > $\left.6 \log _{10} \mathrm{IU} / \mathrm{mL}\right)$, patients with low qHBsAg $(\leq 5,000 \mathrm{IU} / \mathrm{mL})$ had a significantly greater virologic response compared to patients with high qHBsAg levels (qHBsAg > 5,000 IU/mL, p<0.001).

associated with virologic response (Table 4). Compared to patients with qHBsAg levels $<5,000 \mathrm{IU} / \mathrm{mL}$, patients with greater qHBsAg levels had a significantly lower cumulative virologic response $(p \leq 0.001)$ (Fig. $3 A$ ). In $\mathrm{HBeAg}$-positive patients, significantly greater $\mathrm{HBeAg}$ seroclearance was achieved in patients with qHBsAg levels $<5,000 \mathrm{IU} / \mathrm{mL}(p=0.002$ ) (Fig. 3B). Because low viral load is a significant factor in predicting virolog- ic response, patients were grouped into low-viral load (HBV DNA load $\leq 6 \log _{10} \mathrm{IU} / \mathrm{mL}$ ) and high-viral load (HBV DNA load $>6 \times \log _{10} \mathrm{IU} / \mathrm{mL}$ ) groups. In the low-viral load group, there was no significant difference in virologic response based on qHBsAg levels $(p=0.378)$ (Fig. $3 \mathrm{C}$ ). However, there was a significant difference between the virologic response rate in the high viral load group based on low $(\leq 5,000 \mathrm{IU} / \mathrm{mL})$ and high $(>5,000$ 
IU/mL) qHBsAg levels ( $p<0.001$ ) (Fig. 3D). The virologic response of the high viral load group at 6,12 , and 24 months was $46.7 \%, 89.3 \%$, and $98.7 \%$, respectively, in patients with qHBsAg levels $\leq 5,000 \mathrm{IU} / \mathrm{mL}$; and $20.7 \%$, $62.2 \%$, and $84.6 \%$, respectively, in patients with qHBsAg levels $>5,000 \mathrm{IU} / \mathrm{mL}$.

\section{Clinical safety}

There were no serious adverse events reported during treatment. The reasons for patient noncompliance included economical difficulties and treatment fatigue after a prolonged adherence period. None of the patients stopped treatment due to problems with side effects.

\section{DISCUSSION}

CHB patients with high levels of HBV DNA have an increased risk for developing liver cirrhosis and hepatocellular carcinoma [3,4]. Therefore, suppression of HBV DNA is a critical goal in treating CHB patients $[5,6]$. Herein we present results from a long-term empirical study and report predictors of virologic response in treatment-naïve CHB patients treated with entecavir.

Genotype $\mathrm{C}$ is associated with a high likelihood of a longer period of persistent hepatitis, which increases the risk of liver cirrhosis and hepatocellular carcinoma $[15,16]$. In genotype C patients, the antiviral efficacy of lamivudine compared to other genotypes had conflicting outcomes [17-20]. Although direct comparison with other genotypes is not feasible because $95.6 \%$ to $100.0 \%$ of HBV patients in Korea are infected with genotype C $[16,21,22]$, it is possible to provide an indirect comparison with entecavir efficacy among the genotypes. The cumulative virologic response rates to entecavir were 80.0\%, 95.6\%, and 99.4\% after years 1, 3, and 5, respectively, which are comparable to previous long-term studies across multiple populations with various genotypes [23,24].

During the treatment period, 56 patients (5.9\%) exhibited an increase in serum HBV DNA loads by $>1$ $\log _{10}$ above the nadir, even after achieving a virologic response to treatment. Among these patients, 42 (42/56, 75.0\%) were noncompliant and resistance mutations were identified in $2.1 \%$ of patients after 5 years of treatment. These results are comparable to those from a pre- viously study by Yuen et al. [25] in which they reported three cases of viral breakthroughs among 222 patients over a 3-year treatment period, and Ono et al. [24] reported a $1.1 \%$ chance of viral breakthrough over a 4 -year treatment period.

It is known that entecavir resistance requires three HBV RT substitutions: rtM204V and rtL180M, plus an additional mutation at $\mathrm{rtT}_{184}, \mathrm{rtS2O2}$, or $\mathrm{rtM}_{250}$ [26]. Among patients with confirmed virologic resistance, seven patients fit this pattern. Interestingly, one of our patients (no. 8) had a different substituting amino acid at $\mathrm{rtL} 180 \mathrm{G}$ that accompanied rtM204V and rtN238H. rt$\mathrm{N} 238 \mathrm{H}$ has been reported to be associated with known adefovir dipivoxil resistance mutations, such as rtN236T and rtA181T/V [27]. Two patients (no. 9, 10) presenting with rtM204I mutations without additional mutations at rtT184, rtS202, or rtM250 experienced a virologic breakthrough. Another patient (no. 11) with rtM204I, rtV173L, and $\mathrm{rtM} 250 \mathrm{~V}$ mutations also experienced a virologic breakthrough. The $\mathrm{rtV}_{173} \mathrm{~L}$ gene has been reported to enhance in vitro viral replication in lamivudine-treated patients [28]. One patient (no. 12) with an rtI169L mutation presented with primary non-response and eventually experienced a virologic breakthrough. Tenney et al. [29] reported that rtI169T substitutions increase the level of entecavir resistance 2- to 3-fold in select cases and rtI169T mutation was thought to be an ancillary or adaptive change to entecavir. To understand these patterns better, future in vitro analyses of $\mathrm{rtI}_{1} 69 \mathrm{~L}$ are needed.

Yang et al. [13] found a reduced risk of liver related events and HCC in entecavir-treated patients who experienced virologic response. A previous study done at our center also found increased HCC risk in patients with incomplete virologic response to treatment [12]. The patients with lower HBV DNA loads and baseline HBeAg-negativity had a significantly greater probability of achieving virologic response $(p<0.001)$. Thus, the two independent factors found to be predictive of virologic response in our study, baseline HBV DNA loads and HBeAg status, are comparable to previous viral efficacy studies of both lamivudine-treated and entecavir-treated patients [24,30-32].

Studies of qHBsAg have shown that titers correlate with serum HBV DNA load and intrahepatic covalently closed circular DNA level, which is the transcriptional template of HBV [33,34]. Low pretreatment serum qHB- 
sAg level has been found to be a predictor of response to pegylated interferon therapy [35]. However, although NUCs are effective in suppressing HBV DNA load, limited data regarding the role of qHBsAg titers are available in patients treated with NUCs. The results of our study revealed that HBV DNA load $(p<0.001), \mathrm{HBeAg}$ status $(p=0.005)$, and qHBsAg levels $(p<0.001)$ are independent predictors of virologic response. These data suggest that qHBsAg level may complement HBV DNA load in predicting virologic response in patients treated with NUCs. In patients with high HBV DNA loads, low qHBsAg titer $(\leq 5,000 \mathrm{IU} / \mathrm{mL}$ ) was associated with a significantly greater virologic response. In low HBV DNA loads, the qHBsAg titer may have less power in differentiating the predictability for virologic response. Thus, qHBsAg titer may be used as an independent predictor of virologic response in patients with high viral loads. Patients with a combination of HBV DNA loads > $6 \log _{10} \mathrm{IU} / \mathrm{mL}$ and qHBsAg levels $>5,000 \mathrm{IU} / \mathrm{mL}$ can be considered to have the greatest risk of a poor virologic response. In HBeAg-positive patients, low qHBsAg titers were also predictors of $\mathrm{HBeAg}$ seroclearance. These results are comparable to those from a study by Lee et al. [36] in which lower levels of qHBsAg predicted HBeAg seroclearance/seroconversion.

Although our retrospective design has limitations, we present a large empirical study of treatment-naïve patients receiving entecavir. There is still limited data on the role of qHBsAg levels and our relatively large sample size and analyses using baseline qHBsAg levels offers new insights into the role of qHBsAg in predicting viral response.

In conclusion, continuous treatment with entecavir for treatment-naïve, genotype-C, CHB patients over 5 years shows an excellent virologic response rate and a low rate of resistance, which is comparable to results from registration trials. Baseline HBV DNA loads, qHBsAg levels, and HBeAg status were predictors of virologic response during entecavir treatment.

\section{KEY MESSAGE}

1. Long-term entecavir treatment is associated with an excellent virologic response and a low rate of entecavir-resistant mutation.
2. Baseline hepatitis B virus DNA load, quantitative hepatitis B surface antigen levels, and hepatitis B e antigen status are predictors of virologic response of entecavir treatment.

\section{Conflict of interest}

No potential conflict of interest relevant to this article was reported.

\section{REFERENCES}

1. Lavanchy D. Hepatitis B virus epidemiology, disease burden, treatment, and current and emerging prevention and control measures. J Viral Hepat 2004;11:97-107.

2. Beasley RP. Hepatitis B virus: the major etiology of hepatocellular carcinoma. Cancer 1988;61:1942-1956.

3. Chen CJ, Yang HI, Su J, et al. Risk of hepatocellular carcinoma across a biological gradient of serum hepatitis B virus DNA level. JAMA 2006;295:65-73.

4. Iloeje UH, Yang HI, Su J, et al. Predicting cirrhosis risk based on the level of circulating hepatitis B viral load. Gastroenterology 2006;130:678-686.

5. Lok AS, McMahon BJ. Chronic hepatitis B: update 2009. Hepatology 2009;50:661-662.

6. European Association for the Study of the Liver. EASL clinical practice guidelines: management of chronic hepatitis B. J Hepatol 2009;50:227-242.

7. Chang TT, Gish RG, de Man R, et al. A comparison of entecavir and lamivudine for HBeAg-positive chronic hepatitis B. N Engl J Med 2006;354:1001-1010.

8. Lai CL, Shouval D, Lok AS, et al. Entecavir versus lamivudine for patients with $\mathrm{HBeAg}$-negative chronic hepatitis B. N Engl J Med 2006;354:1011-1020.

9. Gish RG, Lok AS, Chang TT, et al. Entecavir therapy for up to 96 weeks in patients with $\mathrm{HBeAg}$-positive chronic hepatitis B. Gastroenterology 2007;133:1437-1444.

10. Tenney DJ, Rose RE, Baldick CJ, et al. Long-term monitoring shows hepatitis B virus resistance to entecavir in nucleoside-naïve patients is rare through 5 years of therapy. Hepatology 2009;49:1503-1514.

11. Pol S, Lampertico P. First-line treatment of chronic hepatitis B with entecavir or tenofovir in 'real-life' settings: from clinical trials to clinical practice. J Viral Hepat 
2012;19:377-386.

12. Cho JY, Paik YH, Sohn W, et al. Patients with chronic hepatitis B treated with oral antiviral therapy retain a higher risk for HCC compared with patients with inactive stage disease. Gut 2014;63:1943-1950.

13. Yang SC, Lee CM, Hu TH, et al. Virological response to entecavir reduces the risk of liver disease progression in nucleos(t)ide analogue-experienced HBV-infected patients with prior resistant mutants. J Antimicrob Chemother 2013;68:2154-2163.

14. Korean Association for the Study of the Liver. KASL clinical practice guidelines: management of chronic hepatitis B. Clin Mol Hepatol 2012;18:109-162.

15. Miyakawa Y, Mizokami M. Classifying hepatitis B virus genotypes. Intervirology 2003;46:329-338.

16. Lee JM, Ahn SH, Chang HY, et al. Reappraisal of HBV genotypes and clinical significance in Koreans using MALDI-TOF mass spectrometry. Korean J Hepatol 2004;10:260270.

17. Janssen HL, van Zonneveld M, Senturk H, et al. Pegylated interferon alfa-2b alone or in combination with lamivudine for HBeAg-positive chronic hepatitis B: a randomised trial. Lancet 2005;365:123-129.

18. Inoue J, Ueno Y, Wakui Y, et al. Four-year study of lamivudine and adefovir combination therapy in lamivudine-resistant hepatitis B patients: influence of hepatitis B virus genotype and resistance mutation pattern. J Viral Hepat 2011;18:206-215.

19. Moskovitz DN, Osiowy C, Giles E, Tomlinson G, Heathcote EJ. Response to long-term lamivudine treatment (up to 5 years) in patients with severe chronic hepatitis $\mathrm{B}$, role of genotype and drug resistance. J Viral Hepat 2005;12:398-404.

20. Yuen MF, Wong DK, Sablon E, et al. Hepatitis B virus genotypes $\mathrm{B}$ and $\mathrm{C}$ do not affect the antiviral response to lamivudine. Antivir Ther 2003;8:531-534.

21. Bae SH, Yoon SK, Jang JW, et al. Hepatitis B virus genotype $\mathrm{C}$ prevails among chronic carriers of the virus in Korea. J Korean Med Sci 2005;20:816-820.

22. Kim H, Jee YM, Song BC, et al. Molecular epidemiology of hepatitis B virus (HBV) genotypes and serotypes in patients with chronic HBV infection in Korea. Intervirology 2007;50:52-57.

23. Luo J, Li X, Wu Y, et al. Efficacy of entecavir treatment for up to 5 years in nucleos(t)ide-naïve chronic hepatitis B patients in real life. Int J Med Sci 2013;10:427-433.
24. Ono A, Suzuki F, Kawamura Y, et al. Long-term continuous entecavir therapy in nucleos(t)ide-naïve chronic hepatitis B patients. J Hepatol 2012;57:508-514.

25. Yuen MF, Seto WK, Fung J, Wong DK, Yuen JC, Lai CL. Three years of continuous entecavir therapy in treatment-naïve chronic hepatitis B patients: VIRAL suppression, viral resistance, and clinical safety. Am J Gastroenterol 2011;106:1264-1271.

26. Tenney DJ, Rose RE, Baldick CJ, et al. Two-year assessment of entecavir resistance in lamivudine-refractory hepatitis B virus patients reveals different clinical outcomes depending on the resistance substitutions present. Antimicrob Agents Chemother 2007;51:902-911.

27. Santantonio T, Fasano M, Durantel S, et al. Adefovir dipivoxil resistance patterns in patients with lamivudine-resistant chronic hepatitis B. Antivir Ther 2009;14:557-565.

28. Delaney WE 4th, Yang H, Westland CE, et al. The hepatitis $\mathrm{B}$ virus polymerase mutation $\mathrm{rtV}_{173} \mathrm{~L}$ is selected during lamivudine therapy and enhances viral replication in vitro. J Virol 2003;77:11833-11841.

29. Tenney DJ, Levine SM, Rose RE, et al. Clinical emergence of entecavir-resistant hepatitis B virus requires additional substitutions in virus already resistant to lamivudine. Antimicrob Agents Chemother 2004;48:3498-3507.

30. Lai CL, Chien RN, Leung NW, et al. A one-year trial of lamivudine for chronic hepatitis B: Asia Hepatitis Lamivudine Study Group. N Engl J Med 1998;339:61-68.

31. Liaw YF. Therapy of chronic hepatitis B: current challenges and opportunities. J Viral Hepat 2002;9:393-399.

32. Zoutendijk R, Reijnders JG, Brown A, et al. Entecavir treatment for chronic hepatitis B: adaptation is not needed for the majority of naïve patients with a partial virological response. Hepatology 2011;54:443-451.

33. Nguyen T, Thompson AJ, Bowden S, et al. Hepatitis B surface antigen levels during the natural history of chronic hepatitis B: a perspective on Asia. J Hepatol 2010;52:508513.

34. Thompson AJ, Nguyen T, Iser D, et al. Serum hepatitis B surface antigen and hepatitis $\mathrm{B}$ e antigen titers: disease phase influences correlation with viral load and intrahepatic hepatitis B virus markers. Hepatology 2010;51:19331944.

35. Tangkijvanich P, Komolmit P, Mahachai V, Sa-nguanmoo P, Theamboonlers A, Poovorawan Y. Low pretreatment serum HBsAg level and viral mutations as predictors of response to PEG-interferon alpha-2b therapy in chronic 
hepatitis B. J Clin Virol 2009;46:117-123.

36. Lee MH, Lee DM, Kim SS, Cheong JY, Cho SW. Correlation of serum hepatitis B surface antigen level with response to entecavir in naïve patients with chronic hepatitis B. J Med Virol 2011;83:1178-1186. 